\title{
The uptake of online tools and web-based language resources by freelance translators: implications for translator training, professional development, and research
}

\author{
Dr. Heather Fulford \\ Business School, \\ Loughborough University, \\ Loughborough, Leics, LE11 3TU, UK. \\ Tel. +44 (0)1509 222435 \\ Fax. $+44(01) 1509223960$ \\ E-mail: H.Fulford@1boro.ac.uk
}

\author{
Joaquín Granell Zafra, \\ Business School, \\ Loughborough University, \\ Loughborough, Leics, LE11 3TU, UK. \\ Tel. +44 (0)1509 228842 \\ Fax. +44 (01)1509 223960 \\ E-mail: J.Granell-Zafra@lboro.ac.uk
}

\begin{abstract}
Freelance translators today have at their disposal an ever-increasing array of online tools and language resources, including search engines, electronic mail, dictionaries, document archives, and terminology databases. A survey of working practices has been conducted among UK translators, with responses received to date from around 400 freelancers. Included in the survey was an investigation of the uptake of online services by translators, the findings of which are reported in this paper. These findings indicate that freelance translators have adopted, and are making extensive use of, both general online tools, and more specialised online terminology resources. Less use is being made, however, of mailing lists, document archives, and online machine translation. The paper concludes with a discussion of the findings, together with a number of research questions arising from those findings.
\end{abstract}

Keywords: Internet; freelance translator; translator training; online dictionary; language resources; multilingual database; terminology

\section{Background}

It has been suggested that the Internet is 'significantly affecting the way translators work today', in both the 'way they handle orders' as well as 'how they search for linguistic and encyclopaedic information' (Austermühl, 2001:38). Indeed, Austermühl goes on to assert that the impact of the Internet on the 'research habits' of translators has been so considerable as to warrant being denoted a 'paradigm shift'. Elsewhere, in a discussion referring specifically to translators working alone on a freelance basis or in small groups, the Internet has been hailed as a 'lifeline' for translators, rendered particularly attractive to them because of its cheapness and ease of use (Carter-Sigglow, 1999).

It is certainly true that the advent of the Internet, and the World Wide Web in particular, has put at the disposal of translators an ever-increasing array of online tools and web-based language resources. These tools and resources offer opportunities for supporting translators at various points in their workflow, including work procurement, topic research, client liaison, terminology identification and verification, and the production of draft translations.

As well as the increasing availability of online tools and language resources for the translation community, a number of other factors arguably point to the appropriateness of, and indeed need for, the Internet as a facility for freelance translators to utilise during various aspects of their work today. Such factors include:

\section{Demand for translation services:}

It is widely acknowledged that the demand for translation services is growing (Andrés Lange and Bennett, 2000:203; Austermühl, 2001:4), fuelled by developments such as industry globalisation, 'intensified international competition' (Austermühl, 2001:4), efforts towards closer collaboration between European countries and the growth of the EU, the expansion of the Internet, software localisation initiatives, and technological innovations, such as DVDs with multilingual content. In addition to the growth in demand for translation services, there are also increasing requirements made of translators to produce highquality translations in ever-shorter time periods (Andrés Lange and Bennett, 2000:203). Online tools and language resources provide facilities to help translators produce and deliver their 
assignments more swiftly than was previously possible. Moreover, the Internet access to an extensive range of document and terminology resources to help translators check and improve the quality and accuracy of their output.

\section{Knowledge growth:}

There has been a growth in knowledge in the past few decades, especially in the sciences, engineering and technological domains. This growth has often been accompanied by a plethora of new terms, as well as an increase in the quantity of both paper-based and electronic texts produced to disseminate that knowledge (Fulford, 2001:260). The World Wide Web comprises a massive repository of documents and databases which translators can use for resolving terminology queries, and for identifying and verifying new term coinages and their foreign-language equivalents. Furthermore, it can act as a rich store of background information and reference material to assist translators in the subject field research tasks associated with the production of translation assignments.

\section{Electronic business developments:}

A final factor worthy of mention with regard to translators and Internet is the rise of electronic business in the past few years. It has been widely reported that owners and managers of small businesses have been particularly keen to embrace e-business developments, such as setting up web sites, communicating with clients and suppliers via e-mail, and conducting business transactions online. These developments have given them an unprecedented opportunity to compete on a level playing field with larger enterprises (Daniel, Wilson and Myers, 2002:253), to engage in lowcost marketing activities, and to extend their geographical reach to a wider (potentially worldwide) customer base (Aldridge, Forcht and Pierson, 1997:161; Herbig and Hale, 1997:98; Kiani, 1998:185). For the freelance translator, the Internet provides a means to liaise with clients, to advertise their translation services via web sites, and to attract clients from a wider geographical area. The text-based nature of the 'translation product' renders it a particularly suitable candidate for electronic business operations.

Whilst the various factors outlined above indicate the potential usefulness of a number of online tools and language resources to translators, there is, in fact, very little empirical data available to indicate which of the various online services are actually being employed by translators. The purpose of this paper is to help address this gap by presenting some empirical evidence of Internet adoption by freelance translators. This evidence has been gathered by means of a major survey conducted among translators based in the UK, to which some 400 responses have been received to date from freelance translators. The findings point to some important implications for the design of curricula for trainee translators, for continuing professional development provision for practising translators, and for further research into the design and development of online services for translators.

The survey reported here forms part of a wider three-year research project into the adoption of ICT (Information and Communications Technologies) by UK translators. The project is funded by the EPSRC (Engineering and Physical Sciences Research Council).

The paper is structured as follows: first, an overview of the online services available to freelance translators is provided (section 2). The survey methodology is then outlined (section 3 ). An overview of the findings of the part of the survey relating to Internet use is presented in section 4, followed by a discussion of those findings (section 5). Finally, some concluding remarks are made and some indications given of areas for further research (section 6).

\section{Internet services for freelance translators: an overview}

As Austermühl has noted, translators have 'heterogeneous information needs' (Austermühl 2001:53). For freelance translators, such information needs might include specialist terminology, background information about particular subject fields, client details, information about colleagues and their translation specialisms, and details of potential future work providers. In today's Internet era, there are many Internet services available to translators to help meet those wide-ranging information needs.

The Internet services available to translators may be divided into three broad categories:

- Data and information repositories: These include, on the one hand, repositories of linguistic and/or terminological data, such as online dictionaries, glossaries and terminological databases. On the other hand, there are, on the World Wide Web, repositories of information encoded in language, including for example, online documents such as 
newspapers, specialist journals, publicity material, and organisational web pages.

- Information retrieval and processing programs: These programs include search tools (e.g. search engines) for tasks such as terminology query resolution and document searching. Included also are online machine translation systems for producing draft or information-only translations.

- Communication tools: These tools include e-mail and messaging programs, file transfer applications, and online discussion groups.

Within each of the above three broad categories, there are first, tools and resources that have been designed and developed specifically for translators to use during the process of translation (e.g. multilingual terminological databases produced for translators). Second, there are tools and resources that have been designed for non-translation purposes (whether general or specialist purpose), but which may, nevertheless, be incorporated by translators into their workflow. Included in this latter group are general-purpose dictionaries, specialist journals, search engines, and e-mail applications. A comprehensive study of the adoption of Internet services by translators, such as the one presented in this paper, needs to consider both the translation-specific and the more general tools and resources available to translators.

In order to illustrate the range of Internet services available to translators today, a summary is provided in Table I below of some of the online tools and language resources that might be integrated into various stages of the freelance translator's workflow.

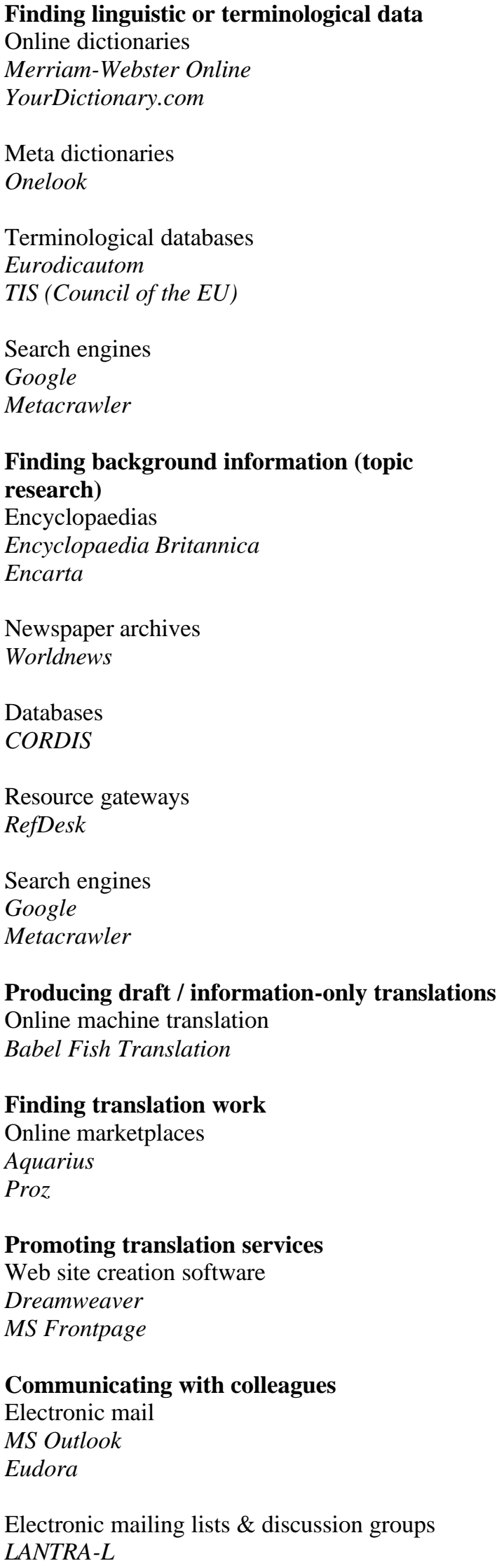

Producing draft / information-only translations

Online machine translation

Babel Fish Translation

Finding translation work

Online marketplaces

Aquarius

Proz

Promoting translation services

Web site creation software

Dreamweaver

MS Frontpage

Communicating with colleagues

Electronic mail

MS Outlook

Eudora

Electronic mailing lists \& discussion groups LANTRA-L

Table I: Online services for translators 


\section{Survey context and method}

The survey discussed in this paper forms part of the exploratory phase of a larger three-year study, which has been established to gain insights into the contemporary working practice of translators, considering in particular their adoption of ICT into the translation workflow. The project aims to identify and examine translators' strategies for integrating computer-based tools and language resources into their workflow, and to assess the impact those tools and resources are having on translation working environments. The specific focus of this paper is on those parts of the project survey relating to the adoption of Internet services by freelance translators.

\subsection{Questionnaire development and validation}

In order to conduct the survey, a draft questionnaire was developed. This questionnaire was based on a review of the relevant literature to identify the range of tools and language resources available to translators today. Since there are few published academic papers explicitly addressing the adoption of information and communications technologies (ICT) by translators, the literature was used primarily as a guide to generate ideas and insights, rather than as a source of specific questions and item measures that could be utilised directly in this study. The resultant questionnaire was organised into the following sections:

Translator profile: demographic data; details of translator training and qualifications; ICT knowledge and skills.

ICT uptake and usage: tools and language resources adopted to date.

Internet usage: uptake of web-based technologies, and general Internet tools to date.

ICT strategy: perceptions of general ICT; perceptions of translation technologies; business planning and strategy issues.

The draft questionnaire was initially validated through a series of pre-tests, first with some experienced researchers, and then, after some modifications, it was re-tested with some translators. The pre-testers were asked to critically appraise the questionnaire, focussing primarily on issues of instrument content, question wording and validity, before providing detailed feedback. The pre-tests were very useful, as they resulted in a number of enhancements being made to the structure of the survey and the wording of specific questions. Having refined the questionnaire, a pilot study exercise was also undertaken, which provided valuable insights into the likely response rate and analytical implications for the full survey.

\subsection{Questionnaire distribution}

There is no official register of translators in the UK. Consequently, an exhaustive list of UK translators was not available for use in the study. For the purposes of this study, however, the sample used for the survey was drawn from a database of 1400 UK-based translators obtained from the membership database of an appropriate professional body. Questionnaires were mailed to the translators in the database of that professional body.

\section{$4 \quad$ Survey Findings}

To date, 590 responses to the survey have been received and logged. Of these responses, 152 were eliminated during a pre-screening exercise on the grounds that the respondents reported that translation is not currently their principal activity, but rather an activity they combine with other undertakings, such as teaching, training, or interpreting. Of the remaining 438 responses, 390 were from freelance translators, and it is the responses of these freelance translators that are the focus of the discussion in this paper. In comparison with other studies of translators undertaken in recent years, both the response rate to this survey and the sample size generated for analysis were encouraging: the sample for Translator's Workbench Project survey, for instance, comprised a total of 110 translators (Fulford, Höge and Ahmad, 1990); and the more recent LETRAC project survey sample consisted of just over 100 'individual translators' (Reuther, 1999).

In this section, some of the findings of the survey are presented, beginning with an overview of the respondents in the sample.

\subsection{Profile of survey respondents}

With regard to educational background, $92 \%$ of the respondents had university-level qualifications, with 53\% of them having postgraduate-level qualifications. A high proportion of the sample $(82 \%)$ had specific qualifications in translation, such as a first degree, master's degree, or a postgraduate-level diploma in translation studies.

With regard to the length of translation experience, responses ranged from 1 to 51 years 
(median: 12 years) spent working in the profession. The most common subject areas translated were business/commerce $(78 \%)$, technical domains $(54 \%)$, and legal issues $(53 \%)$. Productivity varied considerably, ranging from 50 to 100,000 words per week (median: 6000 words). A further measure of productivity showed variations from 0.5 to 84 hours per week (median: 25 hours) dedicated to translation-related tasks. The findings relating to length of translation experience and translator productivity are summarised in Table II below.

\begin{tabular}{|l|ccc|}
\hline & Mean & Median & Mode \\
\hline Years established & 13.95 & 12 & 4 \\
Translated words/week & 7284 & 6000 & 10000 \\
Hours translating/week & 25 & 25 & 40 \\
\hline
\end{tabular}

Table II: Length of experience and productivity

In addition to translation services, some of the translators in the sample offered other services such as linguistic consultancy (15\% of the sample), subtitling/dubbing (15\%), website localisation (14\%), or language training courses (provided by $24 \%$ of the respondents).

The majority of translators in the survey sample were female $(63 \%)$, and the distribution of ages in sample was as follows: 20-29 years (4\%), 30-39 years $(23 \%), 40-49$ years $(30 \%), 50-59$ years $(26 \%)$, and 60 and over $(17 \%)$.

\subsection{ICT skills}

Responses to questions about ICT knowledge revealed that the vast majority $(85 \%)$ of the translators in the sample were self-taught, and most had no formal ICT qualifications. Among those who had formal ICT qualifications, half of them held a professional certificate, while only a few (15\%) had a degree in computing or an ICT-related subject. These findings about ICT skills seem to accord broadly with those reported in the LETRAC project survey (see Reuther 1999).

\subsection{ICT uptake and usage}

Whilst the focus of this paper is on those findings of the survey relating to the uptake of online tools and resources, a brief summary is provided here of the respondents' general ICT adoption and usage.

All of the freelancers in the sample were using computer-based tools to support document production processes (such as word processing software), and $40 \%$ were making use of tools to support business management processes (such as spreadsheet packages, databases or accounting applications). Approximately one third of the translators in the sample were using tools to support terminology management and translation creation (including packages for creating and managing personal terminology collections, and computer-assisted translation tools, such as translation memory). There was little evidence from the findings of translators supporting collaborative work with the use, for instance, of groupware or project management software.

\subsection{Internet connection}

Of the 390 respondents, 97\% used an Internet connection or some other network service giving access to the Internet.

The majority $(66 \%)$ of freelance translators in the sample accessed Internet services via a dial-up connection, with only $31 \%$ using broadband services or a LAN connection. Figure 1 below summarises these findings.

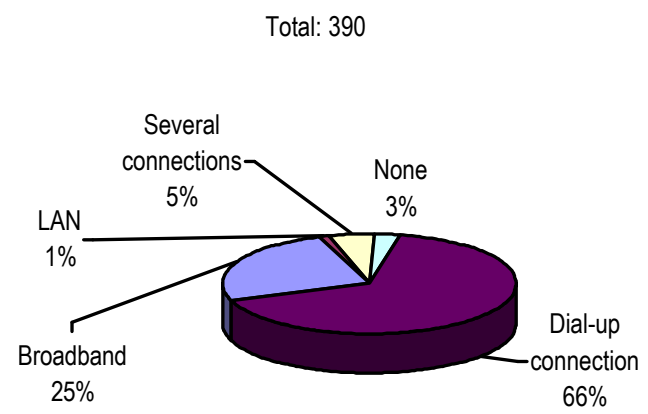

Figure 1. Types of network connection

Further analysis of Internet connections indicated that there was no significant relationship between the types of Internet connection employed and the extent of usage of online tools and language resources.

\subsection{The uptake of online tools and language resources}

In this section, the findings relating to the uptake of online services are presented.

The overriding majority (93\%) of freelance translators in the sample used e-mail. A high proportion $(85 \%)$ used online search engines. A small minority of respondents (3\%) were making use of online machine translation systems. A few were using usenet groups (6\%), and a similar proportion $(6 \%)$ were making use of specialist gateways. There was widespread use of some 
web-based language resources, such as online dictionaries and glossaries $(78 \%)$, and multilingual terminology databases (59\%). Furthermore, quite extensive use was being made of document archives, such as newspaper archives (51\%), but less use of other online resources such as academic journals (30\%), and electronic libraries (27\%). A number of possible reasons can be advanced for the differences among the respondents in their uptake of, for example, newspaper archives (51\%) and academic journals (30\%), including cost issues, levels of resource awareness, and factors such as perceived usefulness of each resource.

As with many studies conducted in an organisational context, the adoption of the survey format restricts the range of issues and constructs that can be explored. It must also be recognised that the results of a survey of this kind are based on statistical analysis and are, therefore, identifying general trends, and measuring 'association' rather than 'causality'. These limitations highlight the need for further research to be conducted that adopts different methods. In particular, there is a need now for a more qualitative study that will allow the statistical patterns and relationships identified in this survey to be more fully explored, and it is hoped, explained empirically. It is precisely this sort of qualitative investigation that forms the next phase of the present research project.

The analysis of the responses is currently being extended to permit the identification of groupings of translator types according to their adoption of, and familiarity with, a range of online tools and language resources. This analysis is being undertaken using the statistical technique of cluster analysis, broadly facilitating the allocation of individual translators to one of several clusters (or groups) in which cluster members tend to share a number of characteristics in common with other cluster members (or are considered in statistical terms to be closely aligned to that cluster).

To date, the following three clusters of translators have been identified in the analysis of the uptake of online tools and language resources (based on 241 responses deemed to be valid for cluster analysis purposes):

Cluster I: Translators make extensive use of email, and some use of search engines and online dictionaries and glossaries. They show some awareness of a broad range of other online terminology resources (such as multilingual terminology databases or online encyclopaedia) and document archives (77 translators in this cluster).

Cluster II: Translators make extensive use of email and search engines, and some use of online dictionaries and glossaries, terminology databases, mailing lists, and to a limited extent use document archives. They show some awareness of a range of other online terminology resources, online communication tools (such as online discussion groups and online translation marketplaces), and a wide array of document facilities (such as academic journals, archives, electronic databases, and electronic libraries), but do not demonstrate an awareness of online MT systems (81 translators).

Cluster III: Translators make extensive use of e-mail, search engines, and online dictionaries and glossaries. They make some use of a wide range of other online terminology resources (such as multilingual terminology databases and online encyclopaedias), document facilities (such as academic journals, archives, electronic databases, and electronic libraries), and online communication tools (such as online mailing lists, discussion groups, and translation marketplaces). They also show some awareness of online MT systems, usenet newsgroups and specialist gateways (83 translators).

Further analysis of the three clusters revealed, perhaps inevitably, that the younger, leastexperienced translators holding a university qualification in translation (particularly a bachelor's or master's degree) were more likely to be found in cluster III. No clear statistical relationships were found between membership of the clusters and levels of productivity, such as weekly word counts.

\subsection{Translator homepages}

The survey also included a section enquiring about the use translators are making of web sites to promote their own translation services. The findings here showed that only $21 \%$ of the sample had their own home page. One might suppose that newcomers to the translation profession would run a home page in order to establish themselves in the freelance arena and attract clients, whereas those who had already been operating an established translation business for some years might not need to do this. The data from this survey, however, did not show any such relationship. Indeed, further analysis of the data here revealed that the uptake of home pages varied little with length of translation experience. Similar findings were found when 
looking at relationships between home page and age of translators in the sample.

Having presented a summary of the survey findings relating to the uptake of online services, a brief discussion of those findings is provided in the next section of the paper.

\section{Discussion}

As indicated in the summary of findings above, the three clusters contained a broadly similar number of translators. They suggest three groupings of translators: first, those who largely utilise general-purpose online tools for terminology retrieval purposes, and who make some use of online versions of conventional lexical and terminology resources, such as dictionaries and glossaries. They have not ventured far into exploring new resources and new tools. Second, there are those who use general-purpose online tools and quite a broad range of online resources for terminology retrieval; they also, to some extent, use other specialist facilities such as mailing lists, but again have not ventured far into the exploration and adoption of these. Third, there are those who use general-purpose online resources, a broad range of online terminology resources, and who also utilise online document archives, as well as a range of different collaborative tools such as mailing lists, discussion groups and online marketplaces. Those in the third grouping thus show a greater awareness, and higher level of uptake, of a broad range of resources than those in grouping one or two. This suggests that those in the third grouping are incorporating online services into a greater range of tasks and processes in their workflow.

Overall, the findings seem to suggest that the translators in the sample are making more use of online services for information retrieval, particularly terminology retrieval, purposes, than they are either for supporting collaborative work, or for marketing and work-finding purposes. Possible reasons for this are being explored in the next phase of the research project.

It was evident from the findings that younger, less experienced translators holding university degrees in translation tended to be using a broader range of Internet services than their more established counterparts. Assuming that these newcomers to the profession acquired their knowledge of Internet services through their university training, it is clear that universities have been adapting and tailoring their courses to reflect the increasing availability of Internet-based facilities to support various aspects of the translation workflow. Given the changing nature of the translation profession, coupled with general advances in online services and virtual working environments, it will be important for these academic institutions to continue to adapt and innovate in order to prepare their student translators for future web-based collaborative workflows. Examples here might include group translation projects and the use of shared translation memory.

Whilst the findings of the exploratory survey presented in this paper have helped to provide a picture of the adoption of Internet services by UKbased freelance translators, they raise a number of questions regarding reasons for adoption or nonadoption. Such questions include:

- Cost issues and availability of free services: is cost a motivating factor for freelance translators when selecting an Internet service?

- Perceived usefulness: what is the perceived usefulness of various Internet services, and how does their usefulness compare with more conventional tools and resources?

- Ease of use: how easy do freelance translators find Internet services to use? What problems have they encountered when using them to date? Do their experiences to date influence their willingness to adopt further services?

- External factors: to what extent do clients require, or encourage, the use of certain Internet services? What role do team-working environments play in encouraging the adoption of Internet services?

- Online translator communities: what role do online translator communities play in encouraging the adoption of online services?

These questions are among those now being investigated using a more qualitative-based study, including in-depth interviews with individual translators.

The findings of the survey indicated that although some translators are aware of a number of 
Internet services, they have not adopted them into their workflows. This discrepancy between usage and awareness highlighted another area for further investigation in the next phase of the research project: why have translators not moved from awareness to usage? Furthermore, the survey findings suggested that translators tend to be aware of some Internet services and not others. From the point of view of translator training and ongoing professional development, it will be important to identify the factors that influence awareness of each type of service: how have translators become aware of certain services, for example?

A final issue that the survey raises is that of the benefits being gained by translators from the various Internet services they have adopted. Again, this is now being explored in the next phase of the project. It is anticipated that the findings regarding benefits will be of particular importance to translator trainers and providers of ongoing professional development materials to help guide and inform their future planning of courses or modules on Internet services. Moreover, a wider understanding of benefits being realised from Internet services could be useful for sharing successful practice strategies among existing professional translators.

Whilst the survey has focussed on UK-based translators, it is envisaged that the survey instrument now designed, developed and validated, could be employed for replication studies among translator communities in other countries. Indeed, undertaking comparative studies among translators in other countries would represent an interesting avenue for further research.

\section{Conclusions}

In this paper, an overview of online tools and language resources for translators was presented. A study was outlined in which the uptake of these online services by freelance translators in the UK was explored. The findings of that study suggested that translators are making more use of online services for information retrieval, particularly terminology retrieval, purposes, than they are either for supporting collaborative work, or for marketing and work-finding purposes. Further research in this area will include the deeper exploration of the reasons for uptake (or nonuptake) of various online services by the translation community in the UK, as well, it is hoped, as further comparative studies of uptake beyond the UK.

\section{References}

Aldridge, A., Forcht, K. and Pierson, J. 1997. Get linked or get lost: marketing strategy for the internet. Internet Research: Electronic Networking Applications and Policy, 7(3):161-169.

Andrés Lange, C. and Bennett, W. S. 2000. Combining machine translation with translation memory at Baan, In Translating into success: cutting-edge strategies for going multilingual in a global age, $(\mathrm{Ed}$, Sprung, R. C.) John Benjamins Publishing Company, Amsterdam/Philadelphia.

Austermühl, F. 2001. Electronic Tools for Translators, St. Jerome Publishing, Manchester.

Carter-Sigglow, J. 1999. The Internet and the Single Translator. In "Twenty-First International Conference on Translating and the Computer", ASLIB, London.

Daniel, E., Wilson, H. and Myers, A. 2002. Adoption of E-Commerce by SMEs in the UK: Towards a Stage Model. International Small Business Journal, 20(3):253-270.

Fulford, H. 2001. Exploring Terms and their Linguistic Environment in Text: A Domain-Independent Approach to Automated Term Extraction. Terminology, 7(2):259-279.

Fulford, H. 2002. Freelance Translators and Machine Translation: An Investigation of Perceptions, Uptake, Experience and Training Needs. In "6th European Association of Machine Translation Workshop", 117-122, UMIST, Manchester.

Fulford, H., Höge, M. and Ahmad, K. 1990. User requirements study. Final report for Workpackage 3.3, EC ESPRIT II programme for project No. 2315 (Translator's Workbench Project).

Herbig, P. and Hale, B. 1997. Internet: the marketing challenge of the twentieth century. Internet Research: Electronic Networking Applications and Policy, 7(2):95-100.

Kiani, G. R. 1998. Marketing opportunities in the digital world. Internet Research: Electronic Networking Applications and Policy, 8(2):185-194.

Reuther, U. 1999. LETRAC survey findings in the Industrial Context. Deliverable D2.2. 